\title{
El interés superior del niño y la prescripción de la obligación alimenticia
}

Ana María Olguin Britto*

\section{SUMILLLA}

El Tribunal Constitucional estableció que el plazo de prescripción de las pensiones alimenticias contemplado en el artículo 2001, inciso 4, del Código Civil es inaplicable respecto de las demandas que afecten las pensiones fijadas en sentencias y en favor de menores de edad. Esta resolución es compartida por la autora; sin embargo, no concuerda con sus fundamentos expuestos, toda vez que debió resaltarse la eliminación de la falta de necesidad respecto de quien no actúa a título personal como sustento de la prescripción; debiendo privilegiarse al máximo una interpretación conforme al principio de interés superior de niño.

\section{INTRODUCCIÓN}

La problemática que surge en el Derecho peruano en torno al Derecho de familia amerita una valoración desde las distintas ramas del Derecho y muestra la necesidad de una reflexión integradora al respecto.

Recientemente el Tribunal Constitucional del Perú se ha pronunciado sobre la prescripción en ejecución de sentencia del proceso de alimentos, confrontando las normas internas y haciendo énfasis en los derechos humanos, especialmente, en los tratados internacionales suscritos por el Estado peruano favorables al niño y al adolescente ${ }^{1}$.

La sentencia referida nos permite hacer unas consideraciones sobre la prescripción de la obligación alimentaria y el interés superior del niño, principio que combina una tutela internacional y nacional.

Los aportes que a continuación desarrollamos, ciertamente, no agotan la reflexión sobre esta problemática, simplemente intentan brindar una contribución al debate actual.

\footnotetext{
${ }^{1}$ Tribunal Constitucional peruano. Exp. № 02132-2008-PA/TC.
} 


\section{ALgunAS CUESTIONES A TENER EN CUENTA EN RELACIÓN A LA PRESCRIPCIÓN DE LA ACCIÓN DE LA PENSIÓN ALIMENTARIA}

El artículo 1989 del Código Civil vigente señala que: "La prescripción extingue la acción pero no el derecho mismo".

Sobre el particular, Rubio Correa señala que: "La prescripción extintiva es una institución jurídica según la cual el transcurso de un determinado lapso extingue la acción que el sujeto tiene, para exigir un derecho ante los tribunales" 2 . Se entiende que si durante un determinado tiempo el posible titular de una acción se ha abstenido de ejercerla, se presume su probable abandono o desinterés.

Respecto al tema que nos atañe, encontramos en nuestro ordenamiento jurídico el artículo 2001 del Código Civil, que establece un plazo de prescripción de dos años para acciones que provienen de pensiones alimenticias ${ }^{3}$.

El derecho a los alimentos es inherente a la persona y es, por lo tanto, un derecho imprescriptible ${ }^{4}$. Esto significa que quien tiene derecho a estos, no los perderá aunque pase el tiempo sin haberlos reclamado, pues "el fundamento de la imprescriptibilidad del derecho a los alimentos radica en que se trata de un derecho que nace y se renueva en forma permanente, ya que diariamente se modifican las necesidades del alimentado"5.

La legislación peruana, respecto a los alimentos, lo define como: "[L]o que es indispensable para el sustento, habitación, vestido y asistencia médica, según la situación y posibilidades de la

\footnotetext{
${ }^{2}$ RUBIO CORREA, Marcial. La extinción de acciones y derechos en el Código Civil. Cuarta edición, Fondo Editorial PUCP, Lima, 1997, p. 16.

${ }^{3}$ Código Civil Artículo 2001.- Prescriben, salvo disposición diversa de la ley:

(...)

4.- A los dos años, la acción de anulabilidad, la acción revocatoria, la que proviene de pensión alimenticia, la acción indemnizatoria por responsabilidad extracontractual y la que corresponda contra los representantes de incapaces derivadas del ejercicio del cargo.

${ }^{4}$ El concepto de alimentos implica todo aquello que le permita al menor satisfacer sus necesidades básicas (alimentos, educación, vivienda, transporte, vestido, asistencia médica, esparcimiento, etc.).

${ }^{5}$ BELluSCIO, Augusto C. Manual de Derecho de Familia. Tomo II, sexta edición, Depalma, Buenos Aires, 1998, citado por BELLUSCIO, Claudio. La prestación alimentaria. Régimen jurídico, Universidad, Buenos Aires, 2006, p. 62. La obligación alimentaria, constituye un supuesto de las denominadas "obligaciones periódicas", que son aquellas que naciendo de una causa o antecedente único, brotan o germinan por el transcurso del tiempo, importando así cada una de las cuotas una deuda distinta. Quien tiene derecho a los mismos, aunque no los reclame por largo tiempo, no pierde ese derecho, ya que la acción por alimentos no se funda en necesidades pasadas sino en las actuales del alimentado.
} 
familia. Cuando el alimentista es menor de edad, los alimentos comprenden también su educación, instrucción y capacitación para el trabajo" (artículo 472 del Código Civil); y además como: "lo necesario para el sustento, habitación, vestido, educación, instrucción y capacitación para el trabajo, asistencia médica y recreación del niño o adolescente. También los gastos de embarazo de la madre desde la concepción hasta la etapa del post-parto" (artículo 92 del Código de los Niños y Adolescentes) ${ }^{6}$.

La obligación alimenticia se funda en la filiación; es decir en la relación paterno filial derivada del acto natural de la procreación, no sólo deriva de la patria potestad, por lo que aún cuando los padres hayan sido privados de ésta, la obligación se mantiene ${ }^{7}$. En este sentido, conviene referir que "la prestación alimentaria (...), no está sujeta entonces, (...) a la prueba de la necesidad por parte del reclamante" 8 .

Es importante resaltar además que la obligación alimenticia corresponde a ambos cónyuges por igual" . El artículo 235 del Código Civil señala que: "Los padres están obligados a proveer al sostenimiento, protección, educación y formación de sus hijos menores según su situación y posibilidades".

Respecto a la prescripción de la acción para cobrar cuotas atrasadas de las pensiones alimenticias declaradas por el juez, es importante señalar que existen dos posturas con diferentes matices.

Una postura, -quizás mayoritaria- sostiene que permitir la acumulación de pensiones que no fueron reclamadas oportunamente, por un lapso extenso o -al menos- considerable, importaría contrariar los fines sociales y económicos de la ley, haciendo más onerosa la condición del obligado

\footnotetext{
${ }^{6}$ El artículo 473 del Código Civil, modificado por Ley $\mathrm{N}^{\circ} 27646$, establece que "el mayor de dieciocho años sólo tiene derecho a alimentos cuando no se encuentre en aptitud de atender a su subsistencia por causas de incapacidad física o mental debidamente comprobadas (...)"; no obstante, al tratarse de los hijos, el artículo 424 del mismo texto legal regula la prolongación de dicha obligación hasta la edad de 28 años en caso que estos últimos sigan estudios de profesión u oficio en forma exitosa y de los hijos e hijas solteros que no puedan atender su subsistencia por causas de incapacidad física o mental comprobadas.

${ }^{7}$ Cfr. BOSSERT Gustavo. Régimen jurídico de los alimentos: cónyuges, hijos menores y parientes aspectos sustanciales y procesales. Segunda Edición actualizada y ampliada, Astrea, Buenos Aires, 2004, p. 191. ${ }^{8}$ Ibídem, p. 213.

${ }^{9}$ El artículo 234 del Código Civil peruano establece que: "El marido y la mujer tienen en el hogar autoridad, consideraciones, derechos, deberes y responsabilidades iguales".
} 
por un cobro sorpresivo que comprenda la acumulación de cuotas alimentarias que no fueron reclamadas con anterioridad ${ }^{10}$.

En ese sentido, la legislación argentina señala que: "La inactividad procesal del alimentista crea la presunción, sujeta a prueba en contrario, de su falta de necesidad y, con arreglo a las circunstancias de la causa, puede determinar la caducidad del derecho a cobrar cuotas atrasadas referidas al periodo correspondiente a la inactividad" $" 11$.

De acuerdo con esta posición se debe tener en cuenta que la finalidad de la prestación alimentaria es satisfacer una necesidad real, actual e impostergable, sería contrario a este objetivo admitir la acumulación de cuotas que no fueron oportunamente reclamadas, haciendo más onerosa la condición del alimentante, exponiéndolo al cobro sorpresivo de sumas que la misma conducta del alimentista pone de manifiesto que no hicieron falta ${ }^{12}$. Por lo tanto, si transcurre un tiempo prudencial y suficiente, se podría llegar a considerar la presunción de falta de necesidad como determinante de la inactividad procesal.

Por lo tanto, no se justifica mantener viva durante un periodo de tiempo una acreencia que presupone una necesidad. "El legislador en su búsqueda de la seguridad jurídica ha considerado que tratándose de un derecho de tal naturaleza, el cobro de la pensión tiene que hacerse dentro del corto plazo que la norma prevé. Me parece así una determinación justa"13.

La excepción sería la demostración de que como en el caso concreto, mediaron circunstancias que permitieron inferir que el alimentista, aún necesitando los alimentos, se encontró dificultado o impedido de reclamar por los atrasos, motivo por el cual, la inactividad procesal no podría interpretarse como desinterés o falta de necesidad, sino todo lo contrario.

Otra postura, es aquella que plantea la imprescriptibilidad de la acción, o en todo caso el optar por el plazo máximo establecido en el ordenamiento jurídico. Al respecto, considera el Tribunal Constitucional peruano que: "Resulta arbitrario que el legislador del Código Civil haya fijado un plazo de prescripción de dos años para aquella acción que nace de una sentencia que fija

\footnotetext{
${ }_{10}^{10}$ BELLUSCIO, Claudio. Ob. cit., p. 235.

${ }_{11}^{1}$ Artículo 645, inciso 2, del Código Procesal Civil argentino.

${ }^{12}$ Cfr. BOSSERT, Gustavo. Ob. cit., p. 523.

13 Tribunal Constitucional peruano. Exp. No 02132-2008-PA/TC, voto de los magistrados Vergara Gotelli, Álvarez Miranda y Urviola Hani, f. j. 6.
} 
una pensión de alimentos, pero que en el caso de la acción que nace de una ejecutoria que fija cualquier otro tipo de pago haya establecido un plazo de diez años"14.

El criterio, que se evidencia de fondo en esta postura, es la plena vigencia, interpretación y aplicación del principio constitucional de protección del interés superior del niño y del adolescente.

Ahora bien, un entendimiento sobre esta segunda posición y, especialmente, respecto del principio referido, amerita una reflexión mayor que sucintamente referimos a continuación.

\section{LA REFERENCIA AL PRINCIPIO DEL INTERÉS SUPERIOR DEL NIÑO EN EL DERECHO PERUANO}

Al respecto, conviene señalar que el ordenamiento nacional e internacional consagra el principio de interés superior del niño y otorga una protección especial a los niños y adolescentes.

Nuestra norma máxima, la Constitución Política, también reconoce una protección especial al niño y al adolescente en el artículo 4. Además, establece en el artículo 6, como objetivo de la política nacional de población, la promoción de la paternidad y maternidad responsable; el deber y derecho de los padres a alimentar, educar y dar seguridad a sus hijos, así como la igualdad de los hijos sin considerar el estado civil de los padres y la naturaleza de la filiación.

El Código de los Niños y Adolescentes ha precisado en el artículo IX que: "En toda medida concerniente al niño y al adolescente que adopte el Estado a través de los Poderes Ejecutivo, Legislativo y Judicial, del Ministerio Público, los gobiernos regionales, gobiernos locales y sus demás instituciones, así como en la acción de la sociedad, se considerará el principio del interés superior del niño y del adolescente y el respeto a sus derechos".

La medida, a la que se hace referencia, debe ser especial en la medida en que un niño o un adolescente no se constituye en una parte más en el proceso, sino una que posee características singulares y particulares respecto de otras, por lo que más allá del resultado del caso, debe procurarse un escrupuloso tratamiento y respeto de sus derechos durante el proceso. Además, la atención debe ser prioritaria, pues el interés superior del niño y del adolescente tiene precedencia en

\footnotetext{
${ }^{14}$ Ibídem, voto mayoritario, f. j. 36.
} 
la actuación estatal respecto de aquellas decisiones judiciales en las que no se encuentran comprometidos sus derechos fundamentales.

Asimismo, es importante señalar que nuestro país desde el año 1990 se encuentra obligado internacionalmente $^{15}$ con la firma de la Convención sobre los Derechos del Niño ${ }^{16}$, que en su artículo 2 establece que los Estados parte tomarán todas las medidas apropiadas para garantizar que el niño se vea protegido contra toda forma de discriminación o castigo por causa de (...) las actividades, las opiniones expresadas o las creencias de sus padres, o sus tutores o de sus familiares.

En el artículo 3 del mismo texto internacional, se establece también, que en todas las medidas concernientes a los niños que tomen las instituciones públicas o privadas de bienestar social, los tribunales, las autoridades administrativas o los órganos legislativos, una consideración primordial a que se atenderá será el interés superior del niño. Además, se establece que los Estados partes, se comprometen a asegurar al niño la protección y el cuidado que sean necesarios para su bienestar, teniendo en cuenta los derechos y deberes de sus padres, tutores u otras personas responsables de él ante la ley y, con ese fin, tomarán todas las medidas legislativas y administrativas adecuadas.

Por su parte, el artículo 4 establece que los Estados partes, deberán adoptar todas las medidas administrativas, legislativas y de otra índole para dar efectividad a los derechos reconocidos en la Convención. En lo que respecta a los derechos económicos, sociales y culturales, los Estados partes adoptarán esas medidas hasta el máximo de los recursos de que dispongan y, cuando sea necesario, dentro del marco de la cooperación internacional.

Otro artículo que resulta relevante resaltar, es el artículo 27 que establece el reconocimiento por parte de los Estados del derecho de todo niño a un nivel de vida adecuado para su desarrollo

\footnotetext{
${ }^{15}$ El artículo 55 de la Constitución nacional señala que los tratados celebrados por el Estado y en vigor forman parte del Derecho nacional. Además, en las disposiciones finales y transitorias se resalta que: "Las normas relativas a los derechos y a las libertades que la Constitución reconoce se interpretan de conformidad con la Declaración Universal de Derechos Humanos y con los tratados y acuerdos internacionales sobre las mismas materias ratificados por el Perú".

${ }^{16} \mathrm{El}$ itinerario internacional del reconocimiento de los derechos del niño se acentúo desde la Declaración de Ginebra de 1924 sobre los Derechos del Niño, la Declaración de los Derechos del Niño de 1959, la Declaración Universal de Derechos Humanos, el Pacto Internacional de Derechos Civiles y Políticos, el Pacto Internacional de Derechos Económicos, Sociales y Culturales, etc. Así, "[e]l niño, por su falta de madurez física y mental, necesita protección y cuidado especiales, incluso la debida protección legal, tanto antes como después del nacimiento". La Convención de las Naciones Unidas sobre los Derechos del Niño fue ratificada por el Estado peruano mediante Decreto Ley N ${ }^{\circ} 25278$ del 04/08/90.
} 
físico, mental, espiritual, moral y social. Además destaca la responsabilidad primordial que tienen los padres u otras personas encargadas del niño de proporcionar, dentro de sus posibilidades y medios económicos, las condiciones de vida que sean necesarias para el desarrollo del niño. El inciso 4 de este artículo, señala que: "Los Estados partes tomarán todas las medidas apropiadas para asegurar el pago de la pensión alimenticia por parte de los padres u otras personas que tengan la responsabilidad financiera por el niño”. Inclusive si viven en países distintos.

El Tribunal Constitucional, además, ya se ha pronunciado al respecto, manifestando que "dentro del orden de prelaciones y jerarquías existente al interior de una Constitución, es decididamente un hecho incontrovertible, que mayor importancia reviste para un Estado y su colectividad, el proteger a la infancia y más aún, si se encuentra en situación de abandono, que promover la seguridad como valor aislado (....) Si una colectividad permite, de espaldas a su propia realidad, que la desprotección a la niñez se solvente con actitudes de indiferencia crónica, lo único que engendra son las condiciones, para que la seguridad que hoy proclama como bandera, no vaya más allá de su propia existencia, como si el futuro de sus descendientes, paradójicamente la seguridad de ellos, no le interesara en lo absoluto" ${ }^{\prime 17}$.

Finalmente, "[e]ste principio regulador de la normativa de los derechos del niño se funda en la dignidad misma del ser humano, en las características propias de los niños, y en la necesidad de propiciar el desarrollo de estos, con pleno aprovechamiento de sus potencialidades (...)"18.

\section{CONCLUSIONES}

Podríamos fundamentar que el artículo 2001, inciso 4, del Código Civil debería ser leído en el sentido de que el plazo de dos años establecido para las acciones de pensiones alimenticias sea interpretado en los casos de los mayores de edad. En el caso de los menores de edad, al tener una protección especial no operaría la prescripción de dicha acción.

Permitir la prescripción de la ejecución de la sentencia sea a los dos o a los diez años, sería avalar la conducta irresponsable de los padres que, amparándose en ésta (prescripción), dejarían de cumplir con la responsabilidad que, por el solo hecho de ser padres, tienen de acuerdo a nuestra legislación y al derecho natural.

\footnotetext{
${ }^{17}$ Tribunal Constitucional peruano. Exp. No 00298-1996-AA/TC.

${ }^{18}$ CORTE INTERAMERICANA DE DERECHOS HUMANOS. Opinión Consultiva OC-17/2002 del 28 de agosto de 2002, solicitada por la Comisión Interamericana de Derechos Humanos, punto 56.
} 
La falta de oportuno reclamo por el alimentista de las cuotas atrasadas, no autoriza la presunción de que carece de necesidad y aún careciendo de esta -por tener alguien que solventa sus necesidades $^{19}$ - no quita la obligación del padre y de la madre de velar por el bienestar físico y emocional del menor, lo que se materializa a través de la institución de los alimentos. La pensión alimenticia no pierde su función y debe seguir siendo exigible. Resulta absurdo señalar que si un menor ha podido solventar sus necesidades durante dos años sin cobrar la pensión que se le asignó, debamos presumir que no necesita el dinero.

Aún en el supuesto de que uno de los padres no accione con la finalidad de cobrar la pensión adeudada al menor representado, no significa que este no tenga la obligación de solventar sus gastos.

El hecho de que la prescripción no alcance a los alimentos que se adeudan a menores de edad resulta razonable, ya que no se debe suponer la falta de necesidad respecto de quien no actúa a título personal, sino que lo hace a través de un representante legal. Es por esto que no puede ni debe declararse la prescripción de las cuotas alimentarias fijadas en favor de los hijos, basadas en la inactividad de la madre o del padre que ejerce la tenencia, pues las necesidades de los hijos menores no pueden ni deben estar sometidas a la poca o mucha diligencia de quien ejerza su representación.

Desde la óptica del alimentista, establecer un plazo corto para reclamar el pago de las cuotas adeudadas es desfavorable -más aún cuando se trata de menores de edad-, ya que perde[ría] más rápido la acción para reclamar el pago de las cuotas atrasadas ${ }^{20}$. Por lo tanto, los fundamentos que sostienen la consideración de un plazo corto de prescripción como el plazo más beneficioso al menor carecen de lógica.

De esta forma, de acuerdo a legislación comparada: "La caducidad no es aplicable a los beneficiarios menores de edad, tampoco, cuando la aparente inactividad del interesado es provocada por la inconducta del alimentante" 21 .

Conviene señalar, también, el papel que el Estado está llamado a asumir subsidiariamente. El inciso 4 del artículo 27 de la Convención sobre los Derechos del Niño, establece que es responsabilidad directa del Estado hacer cumplir a los progenitores o demás obligados la prestación

\footnotetext{
${ }^{19}$ Que podría ser otro familiar o incluso el Estado a través de una institución especial.

${ }^{20}$ Cfr. BELLUSCIO, Claudio. Ob. cit., p. 235.

${ }^{21}$ Artículo 645, inciso 2, del Código Procesal Civil Argentino.
} 
alimentaria. Es por esto que establece que el Estado debe implementar medidas que ayuden a conseguir este fin. Esta obligación que tienen los padres -ambos- frente a sus hijos, muchas veces es incumplida, lo que dificulta su pleno desarrollo.

El Perú, en este sentido viene implementado desde hace unos años el Registro de Deudores Alimenticios Morosos (REDAM) que permite contar con información consolidada de los obligados alimentarios que hayan incurrido en morosidad en el cumplimiento de sus obligaciones alimentarias contenidas en sentencias consentidas o ejecutoriadas o en acuerdos conciliatorios con calidad de cosa juzgada. La finalidad de este registro es persuadir al deudor, toda vez que de acuerdo con la ley, su identidad (con fotografía incluida), aparecerá en la página web del Poder Judicial, además de ser reportada a la Superintendencia de Banca y Seguros en donde es incluida en las centrales de riesgo.

Aún así, los esfuerzos que realiza el Estado peruano resultan insuficientes para lograr la finalidad última que es velar porque la obligación alimenticia a la que se encuentran sujetos los padres sea cumplida.

A modo de conclusión, quisiera señalar que en el presente caso, el Tribunal Constitucional equivocó la estrategia utilizada, habiendo debido interpretar el artículo 2001 del Código Civil, teniendo en consideración el principio del interés superior del niño; y, por lo tanto, hacer una lectura buscando el mayor beneficio posible para los niños y adolescentes. 